
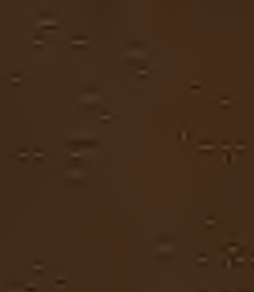


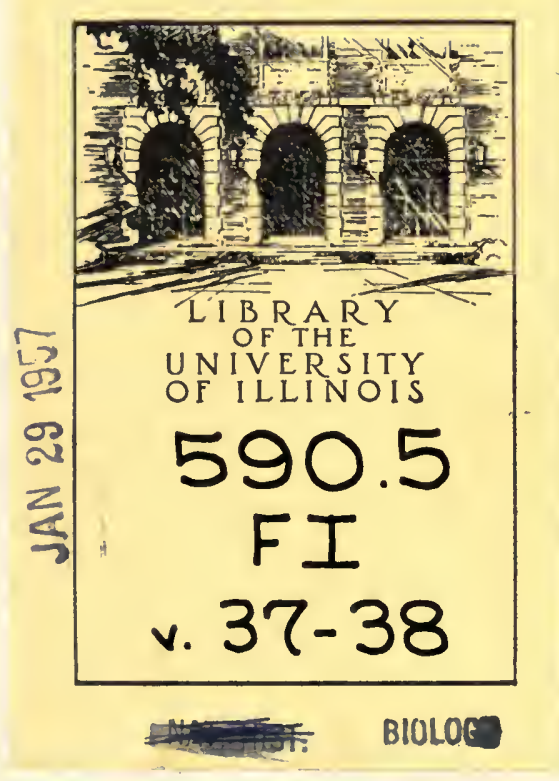


The person charging this material is responsible for its return on or before the Latest Date stamped below.

Theft, mutilation and underlining of books

are reasons for disciplinary action and may

result in dismissal from the University.

UNIVERSITY OF ILLINOIS LIBRARY AT URBANA.CHAMPAIGN

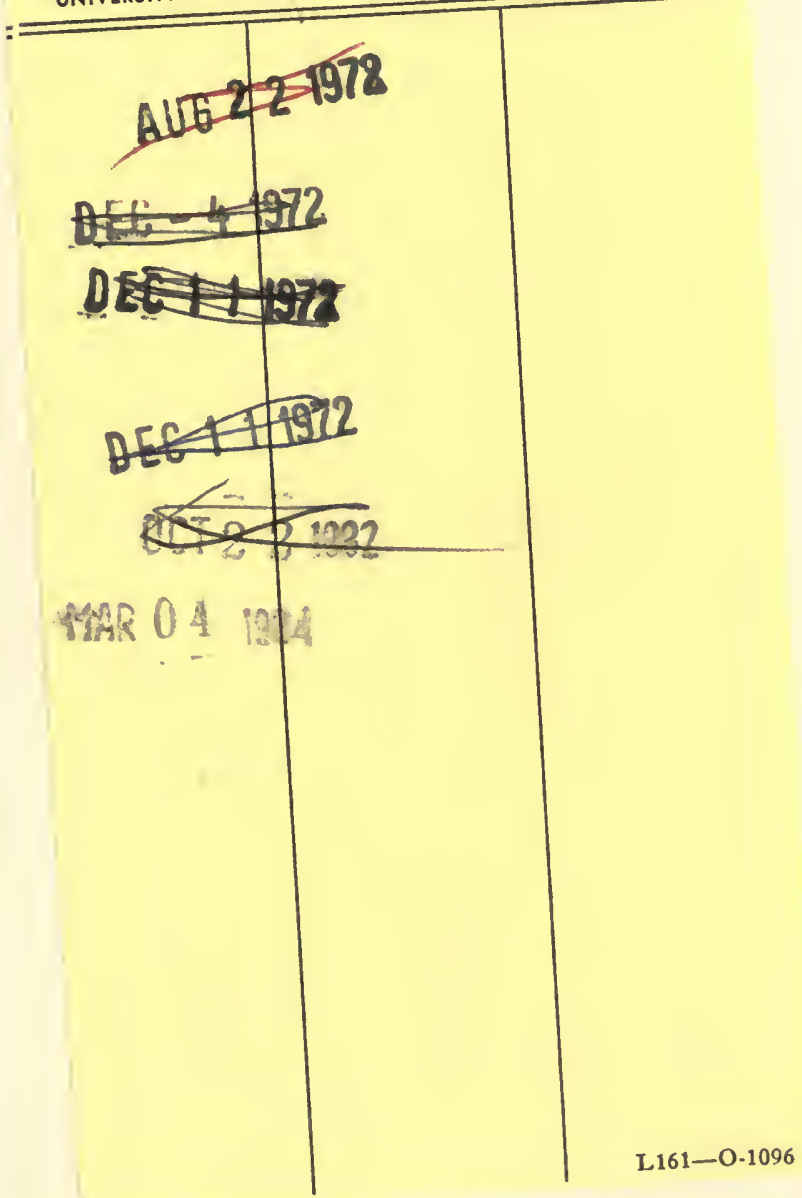







\title{
New Feather-Wing Beetles from Termite Nests in the American Tropics (Coleoptera: Ptiliidae)
}

\author{
HENRY S. DYBAS \\ Associate Curator, Division of Insects
}

No feather-wing beetles were reported from termite nests until 1945, when Silvestri described a new genus, Urotriainus, with two new species and one new variety that he had collected in Brazil, in the nests of several species of termites of the genus Syntermes.

Recent additional collections from termite nests have expanded our knowledge of the Ptiliidae of this interesting habitat. I wish to thank Dr. Alfred E. Emerson of the University of Chicago, Dr. Charles H. Seevers of Roosevelt University, and Mr. R. Araujo of the Instituto Biológico, São Paulo, Brazil, for the opportunity to study most of the specimens that are recorded in this paper. Dr. Emerson identified the host termites, and I am especially grateful to him for this information. The new material includes two new genera of Ptiliidae and a new species placed provisionally in the genus Urotriainus. In addition, some other species from termite nests are recorded, for the relevant data that they provide, but they are not named at present because of insufficient material. Finally, two new groups of host termites are recorded. This new information permits some preliminary conclusions to be drawn about the association of Ptiliidae with termites.

The family Ptiliidae (=Trichopterygidae) contains the smallest beetles and is one of the least known groups of Coleoptera. Spores and hyphae of fungi are the basic foods of the family, and the principal habitat is moist, decaying, organic matter suitable for the development of fungi. Most feather-wing beetles live in forest floor litter, under bark, in tree-holes, rotten wood, decaying fungi, decaying vegetation of other kinds, and animal dung. One specialized group lives only in the spore tubes of growing fungi of the family Polyporaceae. 
The classification of the Ptiliidae is inadequate, and it is not possible to place the termitophilous genera in a satisfactory taxonomic framework. A discussion of the major categories of the Ptiliidae is beyond the scope of the present paper, but some consideration of the affinities of the termitophilous genera is necessary. These genera evidently belong to a single section of the family, together with Ptinella and Pteryx and many other described and undescribed genera. This section, which is probably of subfamily rank, will be termed the pterycine group for the purposes of this discussion. It is distinctive in the following features: elytra abbreviated, exposing several segments of the abdomen; posterior coxae widely separated; mesopleural-metasternal suture arcuate, posteriorly convex; mesosternum simple; and aedeagus of characteristic form (a simple, curved, asymmetrical tube). The abdominal structure furnishes important additional characters, particularly in the condition of the ninth and tenth tergites. Dimorphism is common in the group. In the dimorphic species, in both sexes, there is a "normal" form and a "vestigial" form in which the eyes, wings, and pigmentation of the body are reduced. The vestigial form occurs with the normal form but is usually much more common.

Most of the pterycine genera are associated with decaying wood. The majority of the described and undescribed forms known to me are found under bark, in decaying wood, and in tree-holes.

The two new genera and Urotriainus belong to the pterycine group but evidently represent two separate stocks that have independently adjusted to the termite nest habitat. Despite the small number of records, the evidence strongly suggests that these genera are restricted to this habitat and form a truly termitophilous component of the family Ptiliidae.

One of the new genera, Pycnopteryx, is related to Urotriainus Silvestri. It contains the type species $P$. schmidti sp. nov., taken in numbers in a nest of Syntermes molestus in Colombia, and another species (not described because of insufficient material) taken with Syntermes snyderi in British Guiana.

The described species and variety of Urotriainus were collected in Brazil in the nests of three species of termites of the genus Syntermes of the Nasutitermitinae (Termitidae). The new species, which is placed provisionally in Urotriainus in this paper, was collected in the nest of a different group of termites, the genus Speculitermes of the Amitermitinae. The significance of this difference in host relations is not evident, at present. 
The other new genus, Termitopteryx, is also a member of the pterycine group, but it is not closely related to the two previous genera. It is particularly interesting in that it occurs with termites of the primitive family Kalotermitidae from which few termitophiles are recorded. For example, among the several hundred termitophilous species known, no Staphylinidae are recorded in association with this family of termites.

Little can be said about the special modifications of the Ptiliidae for termitophily. The limuloid body form is a common modification associated with termitophily or myrmecophily, as in the Staphylinidae, for example. Urotriainus and Pycnopteryx gen. nov. have an especially compact, limuloid form and a relatively heavily sclerotized body that is unusual among the few described pterycine genera and may be significant. The highly polished surface, particularly of the head and pronotum, is distinctive. The abdomen appears to be heavily spined in most of the forms and is armed with teeth at the apex in Pycnopteryx and Urotriainus. These modifications, in aggregate, may possibly have some protective value.

Insect guests in termite nests frequently show reduction in certain structures. In the known specimens of Pycnopteryx the eyes lack black pigment and the wings lack the entire membrane but retain the scape. The single specimen of Urotriainus bidentatus lacks most of the marginal hairs of the wing membrane. The significance of these reductions is unknown at present; many nontermitophilous pterycines have "vestigial" forms in which similar reductions of eyes and wings are known. More specimens of the termitophilous species must be studied to decide whether they are dimorphic or not.

Nothing is known of the role of Ptiliidae in the termite society. The gut contents of Urotriainus bidentatus consist of finely comminuted particles in which no distinct cells or fungus spores can be detected. No information about their behavior or the behavior of the host termite toward the beetle is available.

The Ptiliidae described in the following section of this paper bring the number of known termitophilous forms to three genera with five species and one variety. At least two other species are recorded but not named. All the records are from the Neotropical region at present. Feather-wing beetles are minute in size and easily overlooked in the field. Careful collecting in the Neotropics and in other regions of the world will undoubtedly greatly expand the list of termitophilous species. 


\section{Genus UROTRIAINUS Silvestri}

Urotriainus Silvestri, 1945, Comment. pont. Acad. Sci., 9: 552-555.

Genotype.-Urotriainus grandis Silvestri.

Silvestri erected this genus to include two new species and one new variety that he collected in Brazil in the nests of three species of termites of the genus Syntermes. I have not been able to examine any specimens of these species. The types are presumably in the Silvestri Collection in the Laboratorio di Entomologia Agraria "Filippo Silvestri" at Portici, Italy. I am tentatively placing Urotriainus bidentatus sp. nov. in Silvestri's genus on the basis of his descriptions and figures.

\section{Urotriainus grandis Silvestri}

Urotriainus grandis Silvestri, 1945, Comment. pont. Acad. Sci., 9: 556, fig. 15-São Paulo (Jabaquara), São Paulo, Brazil (host, Syntermes grandis Rambur). •

\section{Urotriainus grandis var. robustior Silvestri}

Urotriainus grandis var. robustior Silvestri, 1945, Comment. pont. Acad. Sci., 9: 556, fig. 16-Rio de Janeiro (Manguinhos), D.F., Brazil (host, Syntermes dirus Burmeister).

\section{Urotriainus molesti Silvestri}

Urotriainus molesti Silvestri, 1945, Comment pont. Acad. Sci., 9: 557, fig. 17 -Bomfim, Bahía, Brazil (host, Syntermes molestus Burmeister) and Corumbá, Mato Grosso, Brazil.

Silvestri recorded specimens from both localities but evidently restricted the type locality to Bomfim, Bahía, Brazil.

Urotriainus bidentatus sp. nov. Figures 115-117.

The bidentate apex of the abdomen (fig. 115, a) immediately separates this species from the two species and one variety of Urotriainus described by Silvestri.

Form slender, limuloid (fig. 115, a). Color deep brown, grading to pale; legs and appendages pale. Surface highly polished. Head, pronotum, and scutellum with very fine, sparse, pale setae; elytra with stronger, more closely placed pale setae. Derm microscopically aciculate, especially on elytra.

Antennae short, very slightly longer than width of head; form and chaetotaxy as in figure 116, a. Eyes moderately large, pigmented, not prominent.

Wings present; membrane apparently not reduced in size; marginal hairs of wing mostly lacking (in the type), their basal insertions remaining evident. 
Mesosternum (fig. 115, d) with approximately 3 moderately long setae between coxae; mesopleural-metasternal suture marked internally by a rather heavy endoskeletal fold. Metasternum with scattered setae of moderate size, which are smaller laterally; posterior coxae separated by more than twice their width. Metendosternite composed of the characteristic transverse bar and two anteriorly directed arms that are terminated by flat muscle disks; in addition, a
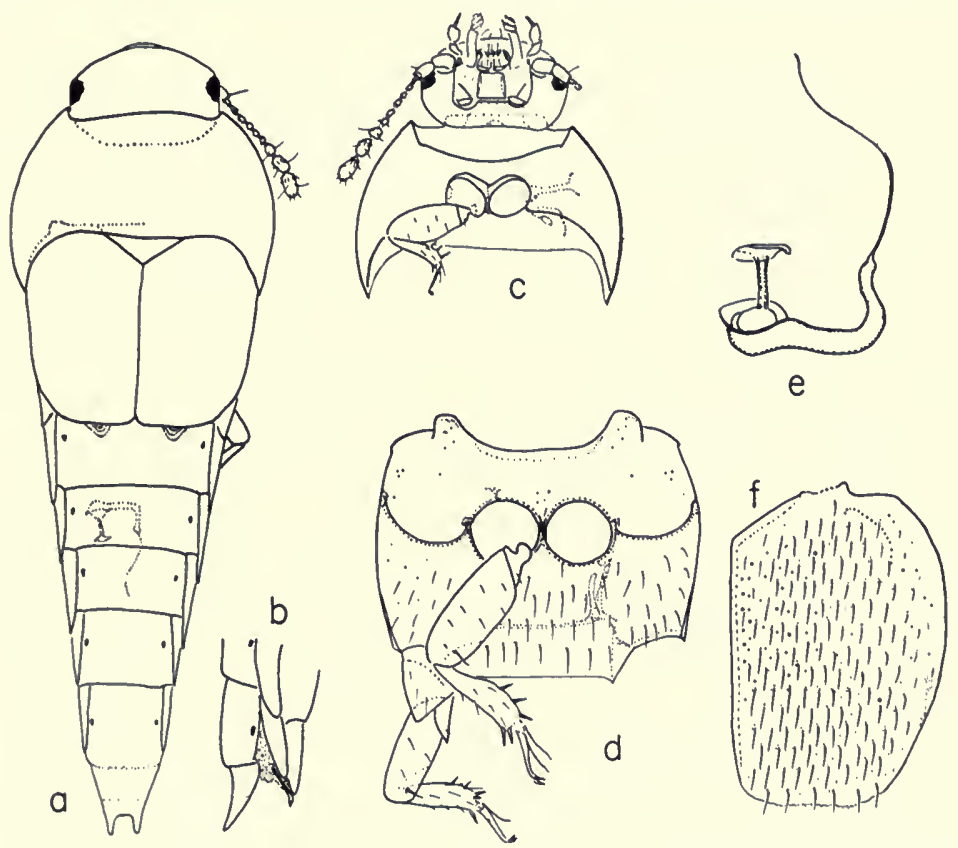

FIG. 115. Urotriainus bidentatus sp. nov. a, Dorsal view $(\times 60)$, chaetotaxy omitted. $b$, Apex of abdomen (lateral view), showing tergites VII (in part), VIII, and fused IX and X; sternites VII, VIII, and the small arcuate sternite IX; and paratergites of segments VII and VIII. $c$, Head and prothorax, ventral view; left leg omitted. $d$, Meso- and metathorax, ventral view; legs omitted on left side. $e$, Spermatheca. $f$, Right elytron.

pair of shorter, anteriorly directed processes arising from the transverse bar ventral to the long arms. No posterior endoskeletal processes arising from the mesocoxal a cetabula are evident.

Legs, in form and chaetotaxy, as in figure 116, $b-d$; all the setae pale; apex of posterior coxal lamina acute; trochanter of posterior leg angulate; each leg with a cleft spine at inner apex of tibia on the posterior face. Apex of tarsus with a membranous lobe arising between the tarsal claws.

Abdomen (figs. 115, $a, b ; 117, a, b$ ) rather heavily sclerotized (except for tergites I-III, which are membranous); apex (tergites IX and X fused) armed with two teeth that are curved upward in profile (fig. 115, b); tergites IV-VIII each with a moderately small spiracle and a paratergite on each side; tergite IV with 
a pair of lateral strigate patches (fig. 115, a) resembling "finger-prints" (also present on membranous tergites II and III); tergite VII with posterior margin microscopically comb-like (fig. $117, a$ ); tergites IV-VIII with 4-5 irregular transverse rows of moderate-sized setae; posterior margin of tergum VIII marked by a series of pores and with a submarginal row of about 7 much larger setae. Tergites IX and X with form and chaetotaxy as in figure 117, $a$.
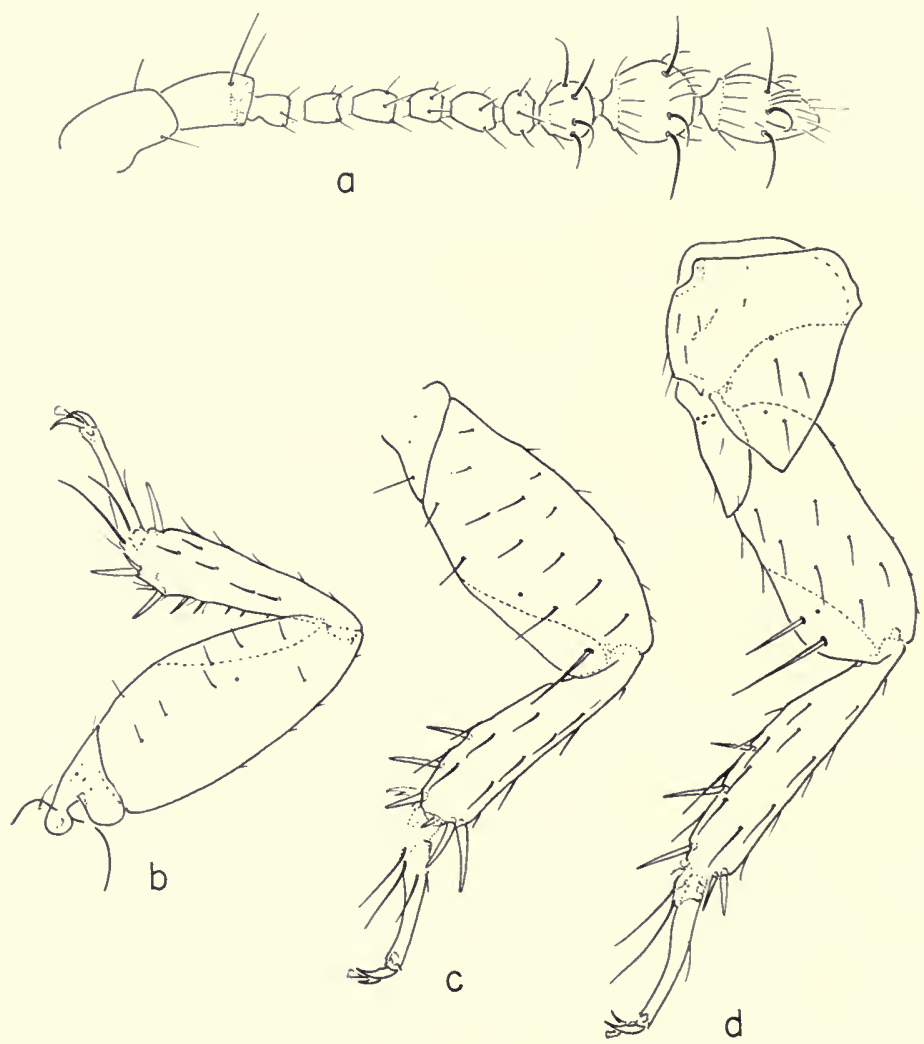

FIG. 116. Urotriainus bidentatus sp. nov. a, Left antenna, ventral view. $b$, Anterior left leg, posterior face. $c$, Middle left leg, anterior face. $d$, Posterior left leg, anterior face.

Sternite III with sharply delimited depressions for the reception of the hind legs; III-VII each with two transverse rows of moderate-sized setae on posterior half; posterior margins very thin and indistinct, but those of VI and VII, at least, minutely scalloped; sternite VIII with posterior margin arcuate, chaetotaxy as in figure $117, b$; sternite IX small, arcuate, broadly emarginate at apex.

Spermatheca in form as in figure $115, e$; its relative size and position in abdomen shown in figure $115, a$. 
Measurements: Width $0.48 \mathrm{~mm}$; length (greatly extended in alcohol) 1.34 $\mathrm{mm}$. Width of pronotum $0.48 \mathrm{~mm}$.; of head $0.27 \mathrm{~mm}$.; of elytron $0.25 \mathrm{~mm}$. Length of pronotum at middle $0.23 \mathrm{~mm}$.

Holotype.-A female (dissected and mounted on 4 microscope slides) from Santo Amaro (Interlagos), São Paulo, Brazil; collected April 7, 1951, by J. F. Prado. Received from R. Araujo (no. 3334).
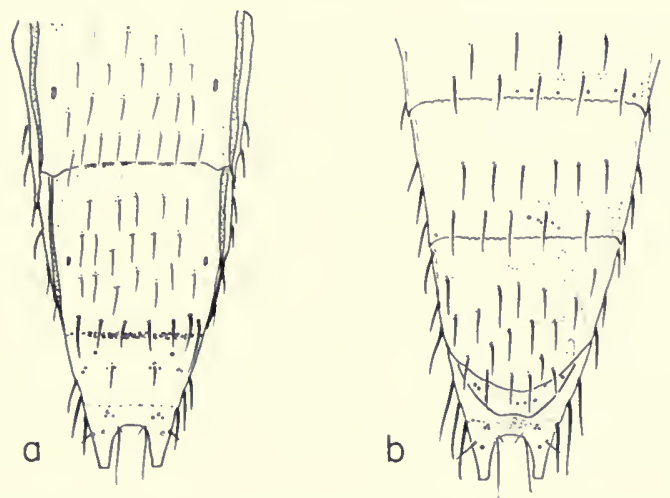

FIG. 117. Urotriainus bidentatus sp. nov. a, Apex of abdomen, dorsal view, showing tergites VII and VIII (and their paratergites on each side), and IX and X (fused). $b$, A pex of abdomen, ventral view, showing sternites VI (in part), VII, VIII, and small arcuate sternite IX, and ventral aspect of tergites IX and X.

In the collection of Chicago Natural History Museum. Host: Speculitermes sp., identified by R. Araujo and A. E. Emerson.

Remarks.-The contents of the intestine consist of finely divided particles containing no recognizable fungus spores or other structures.

PYCNOPTER YX gen. nov. Figures 118, 119.

Genotype.-Pycnopteryx schmidti sp. nov.

Near Urotriainus Silvestri, but differing in the structure of the mesosternum. In Silvestri's figures and description of Urotriainus, the mesocoxal acetabula are contiguous and the mesocoxae are separated by a short longitudinal carina that is not sharply elevated or delimited from the anterior surface of the mesosternum. Pycnopteryx differs conspicuously from Urotriainus in having the mesocoxal acetabula separated (fig. $118, c$ ) though connected internally by an endoskeletal bar, and in having a broad and flat mesosternal "carina" whose anterior margin is broadly triangular in form and sharply delimited from the anterior mesosternal surface, and whose sides partly cover the medial portions of the mesocoxae. 
Minute (but unusually large for the family Ptiliidae) polished beetles of limuloid form (fig. 118, a) with abbreviated elytra, and with apex of abdomen dentate; much smaller but very similar in superficial appearance to Staphylinidae of the subfamily Tachyporinae.

Head broad, deeply inserted into the pronotum to the eyes, its anterior margin forming an arc with the sides of the pronotum. Eyes present (but reduced in size and lacking pigmentation in the genotype). Antennae (fig. 119, a) inserted in deep fossae under the margins of the front just medial to the eyes; 11 -segmented, segments 1-2 large, 3-8 small and moniliform, 9-11 enlarged and furnished with a basal whorl of smaller setae and a median whorl of approximately six large, curved setae in addition to the numerous vesicular and fine, pale setae that are only roughly indicated in figure $119, a$. In repose, the antennae are directed posteriorly under the body, the basal segments being received in a shallow, longitudinal depression on the under side of the head capsule between the eye and the base of the maxilla on each side.

Pronotum (fig. 118, a) strongly convex, its sides vertical; broadly emarginate anteriorly for the insertion of the head; base overlapping the elytra and scutellum; sides evenly arcuate to the acute, greatly prolonged hind angles.

Scutellum very broadly triangular (fig. 118,a), partly covered by the base of the pronotum.

Elytra abbreviated, subtruncate.

Prosternum (fig. 118, $b$ ) short anterior to the coxae (approximately one-half the diameter of the coxae); sides meeting the vertical sides of the pronotum at a very acute angle. Anterior coxal acetabula round, contiguous, open behind.

Mesosternal carina (fig. 118, c) very broad and flat, overlying the medial portion of the mesocoxae; its anterior margin very broadly triangular (the apex of the carina fits against the anterior coxae when the body is contracted) and abruptly elevated from the anterior mesosternal surface. Mesocoxal acetabula round, not contiguous, connected internally by an endoskeletal bar. Mesopleuralmetasternal suture (the suture lateral to the mesocoxae) arcuate, posteriorly convex. Metasternum more than twice as broad as long. Posterior coxae separated by more than twice their width. Metasternum produced between posterior coxae; margin straight. The metendosternite consists of a transverse bar (not easily seen in some slide preparations) and a pair of anteriorly directed arms, each ending in a flat muscle disk. A large funnel-shaped endoskeletal element projects posteriorly from each mesocoxal acetabulum.

Abdomen (fig. 118, a, d) rather heavily sclerotized; apical segment (tergites IX and $\mathrm{X}$ fused) armed with 3 teeth; preceding tergites IV-VIII each with a pair of paratergites and spiracles. Tergum VII with posterior margin microscopically comb-like. Sternum III (the first visible ventral segment) with sharply delimited lateral depressions for the reception of the posterior legs.

Legs moderately short and stout (fig. 119, b-d); posterior coxae subtriangular, laminate, covering much of the retracted femur in repose; trochanter of posterior leg subacute; femora of all legs each with a lamina partly covering the tibia when retracted. Tarsi stout; basal setae strong, not spatulate apically. Claws equal, with a membranous lobe between.

Aedeagus (fig. 118, g) a curved, simple, asymmetrical tube with an apical process. 


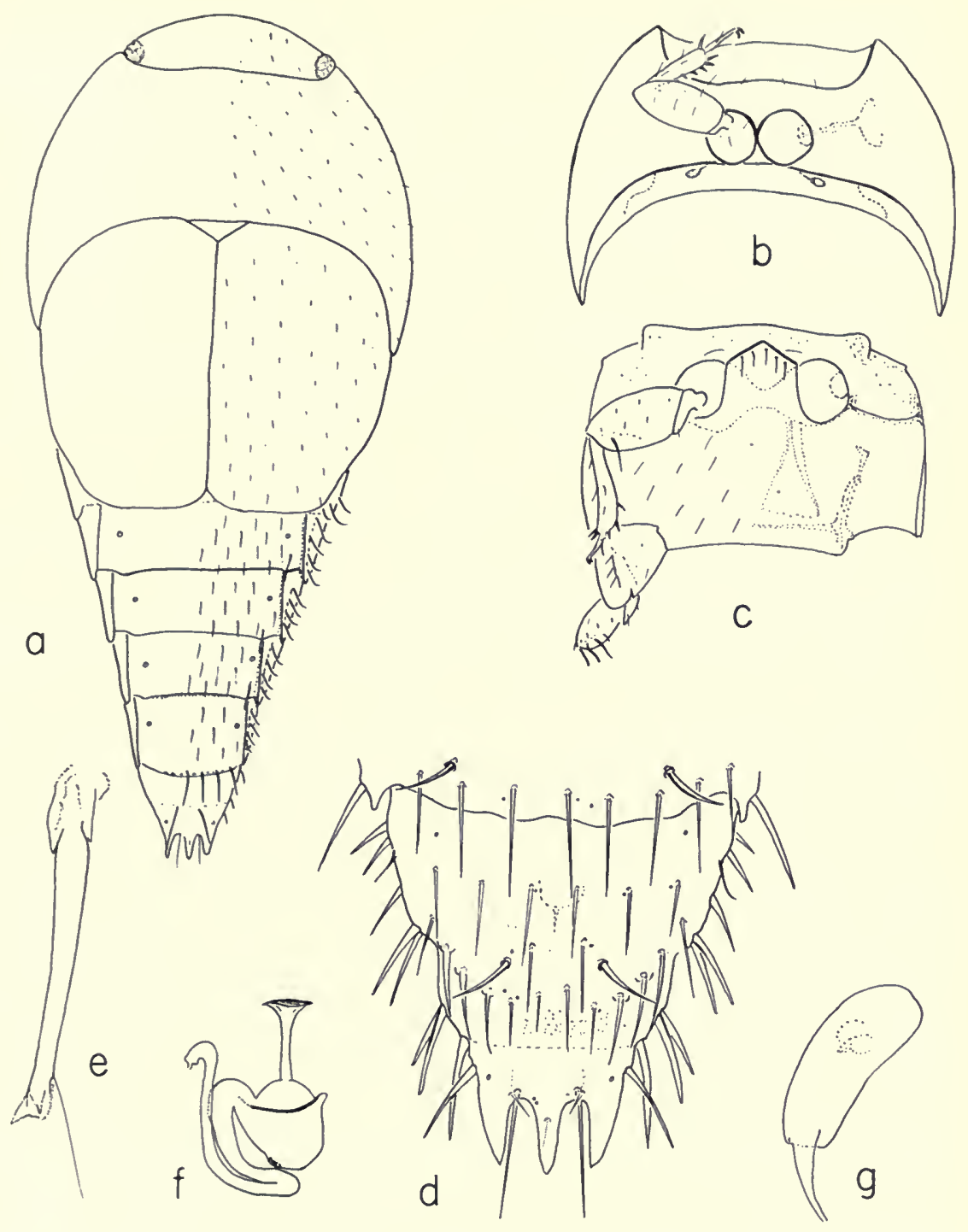

FIG. 118. Pycnopteryx schmidt gen. et sp. nov. $a$, Dorsal view $(\times 60)$; composited drawing. $b$, Prothorax, ventral view; left leg omitted. $c$, Meso- and metasternum, ventral view; legs on left side omitted. $d$, Apex of abdomen, ventral view, showing part of sternite VII, sternite VIII (posterior margin and small sternite $\mathrm{IX}$ indistinct), and ventral aspect of tergites IX and $\mathrm{X}$. $e$, Vestigial wing (right); bristle is at anterior edge of distal end of scape. $f$, Spermatheca. $g$, Aedeagus, ventral view.

569 
Spermatheca (fig. $118, f$ ) tubular, with a bulbous enlargement at the attachment of the spermathecal "pump."

Remarks.-In addition to the genotype, $P$. schmidti sp. nov., I have seen a single male specimen of an allied species of Pycnopteryx taken with Syntermes snyderi Emerson in British Guiana, by A. E. Emerson. The specimen is defective, but it clearly represents a distinct species. The occurrence of this second species in British Guiana in the nests of another species of the host genus Syntermes, is strong additional evidence that Pycnopteryx is an obligate termitophilous genus of Ptiliidae. It further suggests that species of Pycnopteryx may be restricted to particular host species of Syntermes.

\section{Pycnopteryx schmidti sp. nov. Figures 118, 119.}

Color deep brown grading to pale on sides of thorax, apical half of abdomen, head, and appendages. Surface highly polished. Head, pronotum, scutellum, and elytra furnished with very fine, very sparse setae.

Antennae short, about equal in length to the width of the head; form and chaetotaxy as in figure 119, a. Eyes reduced, not pigmented; facets present but indistinct.

Wings vestigial (fig. 118,e), membrane lacking, the basal scape remaining intact (about six examples dissected). Mesosternal carina with approximately 5 setae placed just behind the anterior edge. Metasternum with sparse scattered setae.

Legs with form and chaetotaxy as in figure $119, b-d$. All the setae pale in color; each leg with a cleft spine at the inner apex of the tibia on the posterior face. Basal tarsal segments indistinct, but apparently two in number. The longitudinal series of spines on the posterior coxal lamina is inserted on a fine stria.

Abdomen (in extended specimens in alcohol) with tergites $\mathrm{V}-\mathrm{X}$ exposed; tergites III-VIII with spiracle and paratergite on each side, furnished with 3-4 irregular transverse rows of moderate-sized setae and with a much larger spine just inside each posterior angle at the position of an angulate production of the posterior margin. Each paratergite with a longitudinal row of 4-5 spines that become progressively larger posteriorly. Margin of tergite VIII arcuate, marked with a linear series of pores, and bearing a marginal row of 6-8 strong spines that are much larger medially. Tergites IX and $\mathrm{X}$ fused (the suture distinct in slide preparations); tridentate at apex (fig. $118, d$ ); in addition to the marginal spines visible in the ventral view, tergite $\mathrm{X}$ bears a dorsal pair of heavy spines on the disk.

Sternite III (the first visible segment) with lateral depressions on each side (for the reception of the hind legs) sharply separated by a carina from the median elevated portion; an irregular, transverse row of moderately strong setae at the posterior margin. Sternites IV-VII with two regular transverse rows of moderately strong setae; posterior margins distinctly wavy. Sternites VII and VIII each bearing a sub-median pair of semi-erect setae in addition to the recumbent spines (fig. 118, d). Sternite IX difficult to see and interpret on slide 
preparations. Form and chaetotaxy of terminal part of abdomen from ventral view as in figure 118, $d$ (the small seta visible on the median tooth is inserted on the dorsal surface).

Spermatheca as in figure $118, f$.

Aedeagus in form as in figure 118, $g$.

Measurements: Width $0.52-0.54 \mathrm{~mm}$; length (in alcohol) $1.03-1.29 \mathrm{~mm}$. (depending on the amount of contraction of the abdomen). Width of pronotum
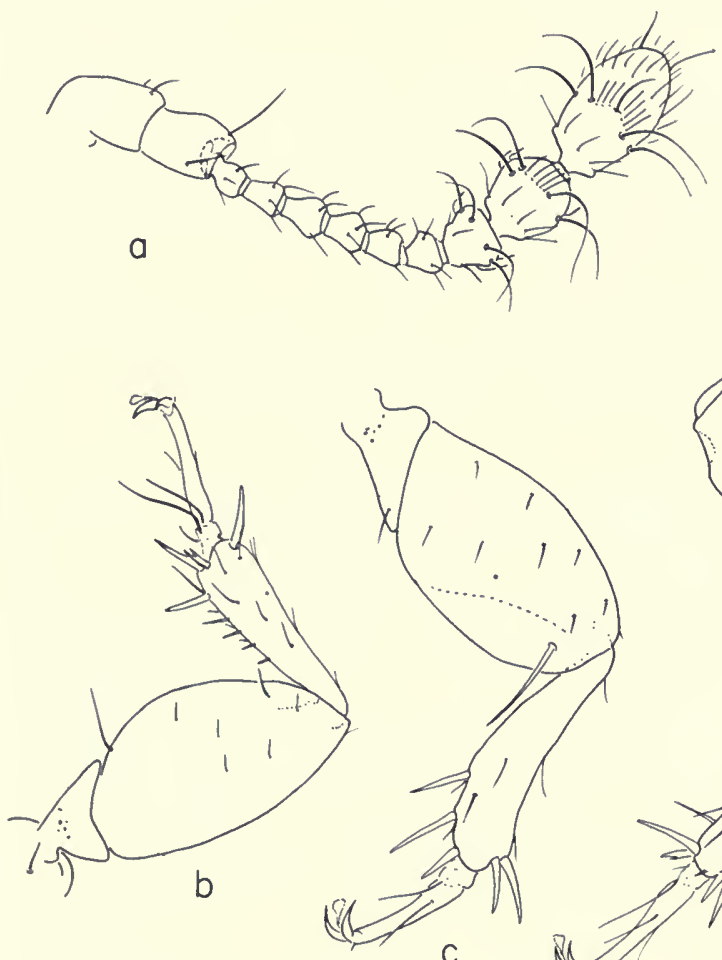

$\mathrm{C}$

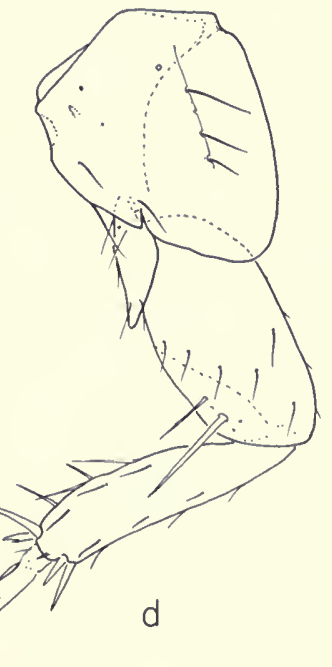

FIG. 119. Pycnopteryx schmidti gen. et sp. nov. $a$, Left antenna, ventral view. $b$, Anterior left leg, posterior face. $c$, Middle left leg, anterior face. $d$, Posterior left leg, anterior face.

$0.54 \mathrm{~mm}$.; of head $0.28 \mathrm{~mm}$.; of elytron $0.30 \mathrm{~mm}$. Length of elytron at suture $0.37 \mathrm{~mm}$.

Holotype.-A female, mounted on a microscope slide, from Villavicencio, Meta Intendencia, Colombia; collected July 16, 1938, by Henry S. Dybas and Charles H. Seevers. In the collection of Chicago Natural History Museum. Host: Syntermes molestus Burm., determined by A. E. Emerson (host termites deposited in 
the collections of A. E. Emerson and Chicago Natural History Museum).

Allotype.-A male, same data as the type.

Paratypes.-Sixteen specimens, same data as the type. One specimen deposited in the collection of the United States National Museum, the remaining 15 specimens in Chicago Natural History Museum.

Remarks. - The host colony of Syntermes molestus was found under a log on the surface of the ground. A large number of galleries and the royal cell containing the physogastric queen were exposed when the log was moved. In addition to the Ptiliidae, the type series of two species of wingless flies of the family Phoridae were found in the same nest: Syntermophora microphthalma Seevers and Cryptophora colombiae Seevers.

This species is named in honor of Dr. Karl P. Schmidt, in evidence of my warm personal and professional regard.

\section{Pycnopteryx sp.}

One male from Kartabo, Bartica District, British Guiana; collected September 25, 1920, in the galleries of Syntermes snyderi Emerson, by Alfred E. Emerson (field no. 347).

The specimen lacks antennae and is defective in other ways. However, it is clearly distinct from $P$. schmidti in a number of features; among others, the tip of the aedeagus differs in being much shorter and much less attenuate, and the posterior margins of the ventral abdominal segments, which are wavy in schmidti, are deeply crenulate in the British Guiana species. The reduction of the wings is similar to that in schmidti; the membrane is lacking but the scape remains intact.

This species is not being described at present because of insufficient material. Nevertheless, the specimen is extremely interesting, for it offers additional evidence of the obligate termitophily of the genus and adds information on the host relations of Pycnopteryx.

TERMITOPTER YX gen. nov. Figures 120, 121.

Genotype.-Termitopteryx productus sp. nov.

A genus of broad, depressed form belonging to the Pteryx-Ptinella group. Pronotum broad, sides evenly rounded, hind angles produced. Abdomen unarmed at apex. Basal segments of tarsi with two pair of spatulate setae. 
Head broad, inserted into the pronotum to the level of the eyes, its anterior margin conforming only moderately to the arc formed by the sides of the pronotum. Eyes prominent, pigmented. Mentum trapezoidal, slightly narrowed apically, sides straight. Antennae (fig. 121, a) inserted in rather deep fossae under the margins of the front, just medial to the eyes; 11-segmented, segments 1-2 large, 3-8 small, elongate, cylindrical, each furnished with an irregular subapical whorl of 4-5 setae; segments 9-11 enlarged, pedicellate, each with a median

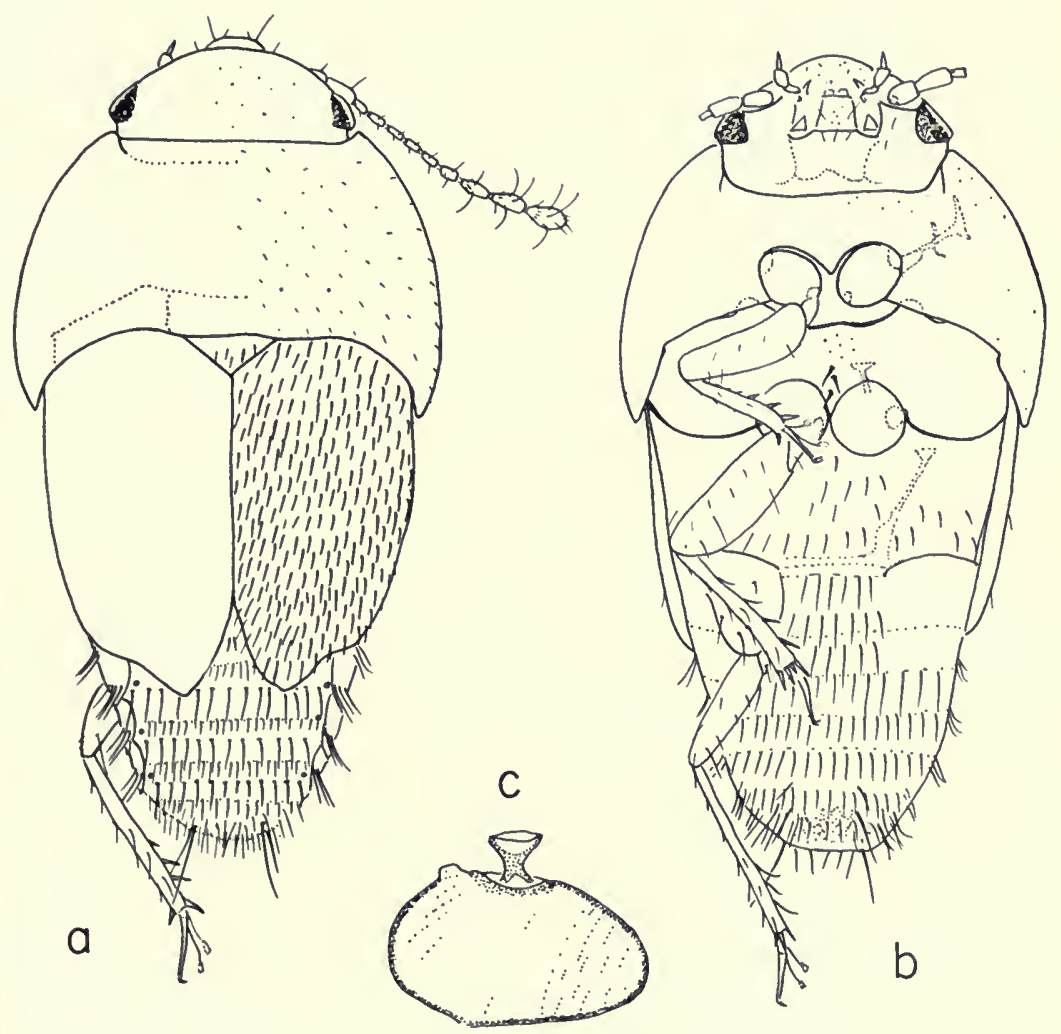

FIG. 120. Termitopteryx productus gen. et sp. nov. $a$, Dorsal view $(\times 65)$. $b$, Ventral view, legs omitted on left side. $c$, Spermatheca (not to same scale as $a$ and $b$ ).

whorl of approximately 6 large, curved setae, and a basal whorl of small setae, in addition to the numerous fine, pale, scattered setae and vesicular setae that are, in part, indicated in figure 121, $a$.

Pronotum (fig. 120, a) broad, depressed (three times as broad as thick); anterior emargination about half of greatest width; base overlapping the scutellum; sides evenly curved to the prolonged hind angles.

Scutellum broadly triangular. 
Elytra abbreviated, exposing several dorsal segments of the apex of the abdomen.

Prosternum short anterior to the coxae, approximately as long as the diameter of the coxae.

Mesocoxal acetabula round, contiguous (fig. 120, b); mesosternum slightly elevated between coxae, not distinctly cariniform and not abruptly delimited or elevated from the anterior mesosternal surface; mesopleural-metasternal suture

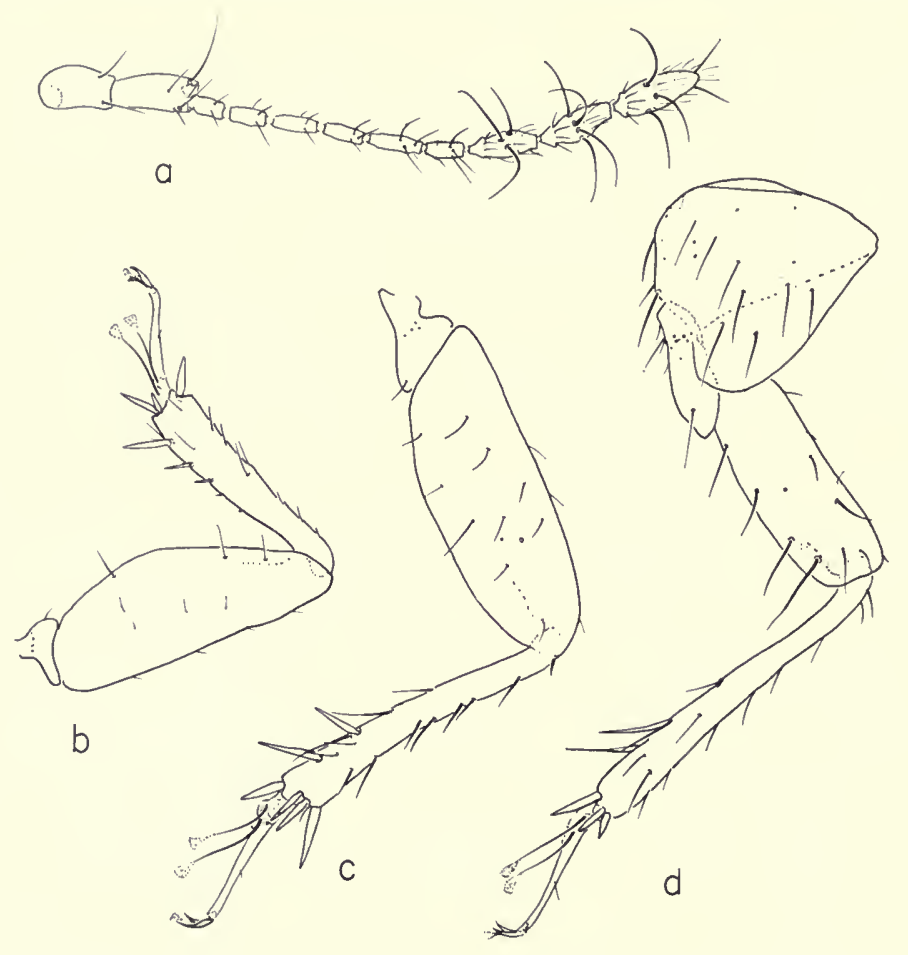

FIG. 121. Termitopteryx productus gen. et sp. nov. a, Left antenna, ventral view. $b$, Anterior left leg, posterior face. $c$, Middle left leg, anterior face. $d$, Posterior left leg, anterior face.

arcuate, posteriorly convex. Metasternum more than twice as broad as long. Posterior coxae broadly triangular, separated by about their width. Metasternum produced between posterior coxae, its margin rather straight.

Abdomen not compact or heavily sclerotized; terminal segment (tergites IX and $\mathrm{X}$ fused, the suture fine but distinct on slide preparations) unarmed; preceding tergites III-VIII each with a paratergite and a spiracle on each side. Tergum VII has the characteristic microscopically comb-like posterior margin well developed.

Sternum III (the first visible ventral segment) without sharply delimited lateral depressions for the reception of the hind legs. 
Legs rather elongate (fig. 121, $b-d$ ); hind coxae triangularly laminate, covering much of the femur in repose. Femora of all the legs with a slight lamina, partly covering the tibiae in repose. Tarsi slender; basal setae (two pairs) long, spatulate apically.

Spermatheca saccular (fig. 120,c).

Remarks. - Like the preceding genera, Termitopteryx belongs to the pterycine group. However, the broad, depressed, lightly pigmented body, the unarmed apex of the abdomen, the form of the antennal segments, the separation of the hind coxae, the leg structure, and other characters indicate that its relationship to the other two termitophilous genera is not close. It represents an independent adjustment to a different group of host termites, the primitive family Kalotermitidae. As mentioned in the introduction, very few termitophiles are recorded from these termites but the records that follow strongly support the conclusion that Termitopteryx is restricted to the Kalotermitidae. On the basis of my material, the genus contains at least two species (though only one is described), which range from Mexico to southern Brazil and occur with three genera of Kalotermitidae.

\section{Termitopteryx productus sp. nov. Figures 120, 121.}

Color translucent brown; eyes black; each folded wing visible through the pale elytron as two longitudinal blackish vittae. Surface shining; head and pronotum smooth, with extremely fine and sparse setae; elytra, scutellum, and abdomen moderately closely covered with golden setae, which become especially long at apex of abdomen.

Antennae moderately long, approximately one-third longer than width of head; form and chaetotaxy as in figure 121, $a$, setae very pale. Eyes prominent, pigmented.

Each elytron distinctively produced at apex near suture (fig. 120,a) (because of the pale, translucent color of the elytron, the shape of the apex is difficult to see except in detached elytra mounted on microscope slide preparations); apex of elytron micro-serrulate (visible only under high magnification).

Wings present, not reduced.

Mesosternum, between mesocoxae, bearing about 4-5 stout spines. Metasternum with scattered setae, which are larger medially.

Legs with form and chaetotaxy as in figure 121, $b-d$; all setae pale in color.

Abdomen with tergites V-VIII each with two transverse rows of setae, the basal row composed of 20-30 smaller setae placed on a fine transverse line, the apical row containing about 12-14 longer and more erect setae; each corresponding paratergite with an oblique row of 4-5 long, strong setae. Tergites IX and X more densely and irregularly covered with setae, each side with an exceptionally long pair with larger basal sockets.

Sternite III (first visible ventral segment) with two short transverse rows of moderately long setae; sternites IV-VII each with a single transverse posterior 
row of moderately long setae; sternite VIII with a rather dense arrangement of long setae, especially at sides, its posterior margin indistinct (sternite IX not distinct). Sternites VII and VIII each with a sub-median pair of long, curved, semi-erect setae.

Spermatheca in form as in figure $120, c$.

Measurements: Width 0.65-0.72 mm.; length $1.20-1.31 \mathrm{~mm}$. (in extended specimens in alcohol).

Holotype.-A female, mounted on a microscope slide, from Ilha Grande, Estado do Rio, Brazil; collected July 7, 1944, by Helmut Sick (field no. 465). Received from Charles H. Seevers. In the collection of Chicago Natural History Museum. Host: Rugitermes arthurimuelleri von Rosen, identified by Alfred E. Emerson.

Allotype.-A male, same data as the type, in the collection of Chicago Natural History Museum.

Paratypes.-Fourteen specimens, same data as the type; one specimen, same locality, October 16, 1944 (field no. 516). Host: Rugitermes sp. probably arthuri-muelleri von Rosen.

\section{Termitopteryx sp. or spp.}

The following five specimens of Termitopteryx, from three separate lots, are related to $T$. productus but differ most conspicuously in the form of the apices of the elytra, which are truncate and not produced, and in the relatively shorter and stouter antennal segments.

One female (in vial with type series of Termitopteryx productus sp. nov.) from Ilha Grande, Estado do Rio, Brazil; collected July 7, 1944, by Helmut Sick (field no. 465). Host: Rugitermes arthurimuelleri von Rosen, identified by Alfred E. Emerson.

One male, one female, labeled St. Catarina, Blumenau [Brazil], from the A. Reichensperger Collection, received from Charles $\mathrm{H}$. Seevers. Host: "Neotermes n. sp. (insufficient material for describing)," identified by Alfred E. Emerson.

Two females from Cuesta de los Cedros, $36 \mathrm{~km}$. east of Ciudad del Maiz, San Luis Potosi, Mexico; alt. 2,250 ft.; "mesophytic oak area"; collected by F. Werner and W. Nutting. Host: Kalotermes jouteli Banks, identified by Alfred E. Emerson.

The specimens are very similar, differing only in relatively minor details (such as slight differences in chaetotaxy). However, since there are only five specimens from three different genera of host termites from very widely separated geographic localities, I am unable to evaluate the slight differences that appear. Under 
these circumstances, the specimens are merely being assigned to the genus and not named. Nevertheless, they add much to our understanding of the genus Termitopteryx. On the basis of these specimens, together with the genotype $T$. productus, the genus appears to be termitophilous and apparently restricted to primitive termites of the family Kalotermitidae, with a range extending from Mexico to southern Brazil. 





FIELDIANA 20010 GYSC

37-38

7-38 1955-58

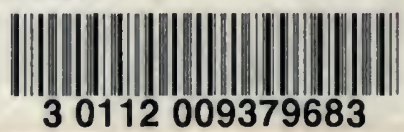

